The University of Maine

\title{
DigitalCommons@UMaine
}

Earth Science Faculty Scholarship

Earth Sciences

8-30-2006

\section{Antarctic Temperatures Over the Past Two Centuries from Ice Cores}

David P. Schneider

Eric J. Steig

Tas D. van Ommen

Daniel A. Dixon

Paul Andrew Mayewski

University of Maine-Main, paul.mayewski@maine.edu

See next page for additional authors

Follow this and additional works at: https://digitalcommons.library.umaine.edu/ers_facpub Part of the Earth Sciences Commons

\section{Repository Citation}

Schneider, David P.; Steig, Eric J.; van Ommen, Tas D.; Dixon, Daniel A.; Mayewski, Paul Andrew; Jones, Julie M.; and Bitz, Cecilia M., "Antarctic Temperatures Over the Past Two Centuries from Ice Cores" (2006). Earth Science Faculty Scholarship. 11.

https://digitalcommons.library.umaine.edu/ers_facpub/11 
Authors

David P. Schneider, Eric J. Steig, Tas D. van Ommen, Daniel A. Dixon, Paul Andrew Mayewski, Julie M. Jones, and Cecilia M. Bitz 


\title{
Antarctic temperatures over the past two centuries from ice cores
}

\author{
David P. Schneider, ${ }^{1}$ Eric J. Steig, ${ }^{1}$ Tas D. van Ommen, ${ }^{2}$ Daniel A. Dixon, ${ }^{3}$ \\ Paul A. Mayewski, ${ }^{3}$ Julie M. Jones, ${ }^{4}$ and Cecilia M. Bitz ${ }^{5}$ \\ Received 30 May 2006; revised 26 June 2006; accepted 24 July 2006; published 30 August 2006.
}

[1] We present a reconstruction of Antarctic mean surface temperatures over the past two centuries based on water stable isotope records from high-resolution, precisely dated ice cores. Both instrumental and reconstructed temperatures indicate large interannual to decadal scale variability, with the dominant pattern being anti-phase anomalies between the main Antarctic continent and the Antarctic Peninsula region. Comparative analysis of the instrumental Southern Hemisphere $(\mathrm{SH})$ mean temperature record and the reconstruction suggests that at longer timescales, temperatures over the Antarctic continent vary in phase with the $\mathrm{SH}$ mean. Our reconstruction suggests that Antarctic temperatures have increased by about $0.2^{\circ} \mathrm{C}$ since the late nineteenth century. The variability and the long-term trends are strongly modulated by the SH Annular Mode in the atmospheric circulation. Citation: Schneider, D. P., E. J. Steig, T. D. van Ommen, D. A. Dixon, P. A. Mayewski, J. M. Jones, and C. M. Bitz (2006), Antarctic temperatures over the past two centuries from ice cores, Geophys. Res. Lett., 33, L16707, doi:10.1029/2006GL027057.

\section{Introduction}

[2] Given the enormous amount of freshwater stored in the Antarctic ice sheet and the impact that temperature changes may have on the ice sheet mass balance, it is important to understand how and why Antarctic temperatures have changed. Several studies have presented summaries of Antarctic temperature change based on instrumental records [e.g., Turner et al., 2005; Jacka et al., 2004; Vaughan et al., 2003]. The Antarctic Peninsula region has experienced some of the strongest surface warming on Earth during the past 50 years, while temperature trends across the continent differ in sign and magnitude among different time periods and seasons [Turner et al., 2005]. Recent cooling across the continent in the summer and autumn has been linked to persistence of the positive index phase of the Southern Hemisphere Annular Mode (SAM) [Thompson and Solomon, 2002]. The recent trend in the SAM has been attributed to various combinations of stratospheric ozone

\footnotetext{
${ }^{1}$ Department of Earth and Space Sciences, University of Washington, Seattle, Washington, USA.

${ }^{2}$ Department of the Environment and Heritage, Australian Antarctic Division, Antarctic Climate and Ecosystems Cooperative Research Centre, Hobart, Tasmania, Australia.

${ }^{3}$ Climate Change Institute, University of Maine, Orono, Maine, USA.

${ }^{4}$ Institute for Coastal Research, GKSS Research Centre, Geesthacht, Germany.

${ }^{5}$ Department of Atmospheric Sciences, University of Washington, Seattle, Washington, USA.
}

Copyright 2006 by the American Geophysical Union. 0094-8276/06/2006GL027057 depletion and rising atmospheric $\mathrm{CO}_{2}$ concentrations [e.g., Thompson and Solomon, 2002; Shindell and Schmidt, 2004], implying anthropogenic influences on Antarctic climate. However, the temporal variability of Antarctic climate is not well known, as continuous meteorological observations in the Antarctic began only in the late 1950s. Quantitative reconstruction of Antarctic temperatures has been faced with several challenges. First, the short and sparse instrumental observations make it difficult to determine how well variations in temperatures at research stations represent regional temperature variations across the continent. Second, while stable isotope time series from Antarctic ice cores are well-known, reaching up to eight glacial cycles into the past [EPICA Community Members, 2004], such records have generally not been available at the high-resolution required for reconstructing the instrumental record. Finally, while statistical reconstruction approaches have been applied in regional to hemisphericscale reconstructions [e.g., Jones and Mann, 2004], such approaches have not been applied to Antarctic data.

[3] New data and improved understanding of the mechanisms explaining Antarctic temperature and stable isotope variations enable the quantitative reconstruction of Antarctic temperatures for the first time. Targeted ice-coring projects, such as the International Trans-Antarctic Scientific Expedition (ITASE), which has the specific objective of collecting numerous high-resolution records, have greatly expanded the availability of proxy indicators of Antarctic climate [Mayewski et al., 2006; Steig et al., 2006]. The aim of this paper is to utilize these new data in a 200-year-long Antarctic temperature reconstruction (representing the main part of the continent) methodologically similar to temperature reconstructions covering other geographic regions.

\section{Data}

[4] For Antarctic surface temperature observations, we use the quality-controlled station records from the Antarctic READER project, which archives continuous monthly observations covering generally the late 1950s to present [Turner et al., 2004]. Time series from eight stations on the coast and the continental interior are included in our analysis, while data from the Peninsula region are excluded due to their location with respect to the main climatic pattern that dominates the continent (see Methods, below).

[5] Subannually-resolved $\delta^{18} \mathrm{O}$ and $\delta \mathrm{D}$ (hereafter denoted " $\delta ")$ ice core records are compiled from Law Dome [van Ommen et al., 2004], Siple Station [Mosley-Thompson et al., 1990], Dronning Maud Land (DML) [Graf et al., 2002], and two West Antarctic sites of the United States component of ITASE [Steig et al., 2006] (Table 1). The Law Dome and DML records are stacks of several records 
Table 1. Ice Core Site Characteristics

\begin{tabular}{|c|c|c|c|c|c|}
\hline Core Name & Latitude & Longitude & Elevation, $\mathrm{m}$ & Time span & Isotope \\
\hline Law Dome 2000 (stack) & $66.78 \mathrm{~S}$ & $112.82 \mathrm{E}$ & 1370 & $1800-1999$ & $\delta^{18} \mathrm{O}$ \\
\hline Siple Station & $75.92 \mathrm{~S}$ & $84.1 \mathrm{~W}$ & 1054 & $1800-1983$ & $\delta^{18} \mathrm{O}$ \\
\hline Dronning Maud Land (several sites) & $\sim 75 \mathrm{~S}$ & $\sim 0 \mathrm{E}$ & $\sim 2900$ & $1800-1997$ & $\delta^{18} \mathrm{O}$ \\
\hline US ITASE 2000-1 & $79.38 \mathrm{~S}$ & $111.23 \mathrm{~W}$ & 1791 & $1800-1999$ & $\delta^{18} \mathrm{O}$ \\
\hline US ITASE $2000-5$ & $77.68 \mathrm{~S}$ & $123.99 \mathrm{~W}$ & 1828 & $1800-1999$ & $\delta \mathrm{D}$ \\
\hline
\end{tabular}

${ }^{a}$ DML cores (documented by Graf et al. [2002]) in the DML stack: DML18(FB9804); DML19(FB806); DML05(FB9807); DML20(FB9808); DML21(FB9810); DML22(FB9811); DML16(FB9813); DML14(FB9815); DML13(FB9816); DML12(FB9817); DML07(B31); DML05(B32); DML17(B33); DML03(FB9809).

from closely-spaced sites in the region. These records have been well-dated through counting of annual layers in ionchemistry and $\delta$ concentrations, and by the identification of volcanic eruption marker horizons. All isotopic data were referenced to the VSMOW and SLAP (Standard Light Antarctic Precipitation) standards from the International Atomic Energy Agency.

[6] We also utilize gridded 2-m temperature (2-m T) data from a polar-adapted mesoscale climate model driven at the lateral boundaries by the ERA-40 Reanalysis over 19802001 [Monaghan et al., 2006] to characterize the spatial variability of Antarctic temperatures.

\section{Methods}

[7] The gridded 2-m $\mathrm{T}$ data are too short in duration to use directly in the reconstruction, but they are used to assess the skill of the station network in representing the variance of Antarctic temperatures. The leading empirical orthogonal function (EOF) of annual mean 2-m T over the continent captures $46 \%$ of the variance (Figure 1a). This "coldcontinent - warm Peninsula" pattern can be interpreted as the expression of the SAM, as illustrated by correlation of the station-based SAM index of Marshall [2003] with the 2-m T field (Figure 1b), or with satellite-derived temperatures [Schneider et al., 2004]. The SAM is a roughly zonally symmetric seesaw in atmospheric mass between the Antarctic and the mid-latitudes, characterized by fluctuations in the strength of the westerly polar vortex [Thompson and Wallace, 2000]. Discussion of the physical mechanisms relating the SAM to temperature anomalies over the ice sheet is provided by van den Broeke and van Lipzig [2004].

[8] EOF analysis of annual station data spanning 19612003 indicates that the first EOF explains $43 \%$ of the total variance, with all stations having positive weights. These results are very similar to the gridded 2-m T data, indicating the robustness of the leading temperature pattern. The first $\mathrm{PC}$ is correlated at $\mathrm{r}=0.98$ with the simple average of the station temperature records. This average, which we call A8, is significantly correlated at $\mathrm{r}=0.76(\mathrm{p}<0.01)$ (degrees of freedom are reduced to account for autocorrelation for the significance of all correlations and trends discussed herein) with the mean of the 2-m $\mathrm{T}$ data over 1980-2001. In addition, the cold continent - warm Peninsula pattern is evident in the correlation of $\mathrm{A} 8$ with the 2-m $\mathrm{T}$ field (Figure 1c), showing that A8 provides a meaningful estimate of temperature variability on a continent-wide scale. While there is not a significant linear trend in $\mathrm{A} 8, \mathrm{~A} 8 \mathrm{de}-$ picts temperature increases in roughly the first half of the series and decreases in the second half (Figure 2), in agreement with other studies of recent Antarctic tempera- ture trends [Jacka et al., 2004; Turner et al., 2005]. A8 is thus our target temperature index for reconstruction; it provides as long and homogeneous a record as is possible from existing Antarctic data.

[9] An advantage of isotopic records over many other climate proxy indicators is that the physics governing their variability is well understood. The relevant processes can be depicted in models ranging in completeness from simple Rayleigh models [e.g., Dansgaard, 1964] and intermediate complexity models [e.g., Kavanaugh and Cuffey, 2003], to full general circulation models (GCM) [e.g., Werner and Heimann, 2002; Noone and Simmonds, 2002]. In Antarctica, most isotope modeling studies have upheld the traditional interpretation of isotope anomalies as indicators of local temperature during precipitation, despite complexities in the processes that control isotope fractionation [Jouzel et al., 1997; Werner and Heimann, 2002]. However, while

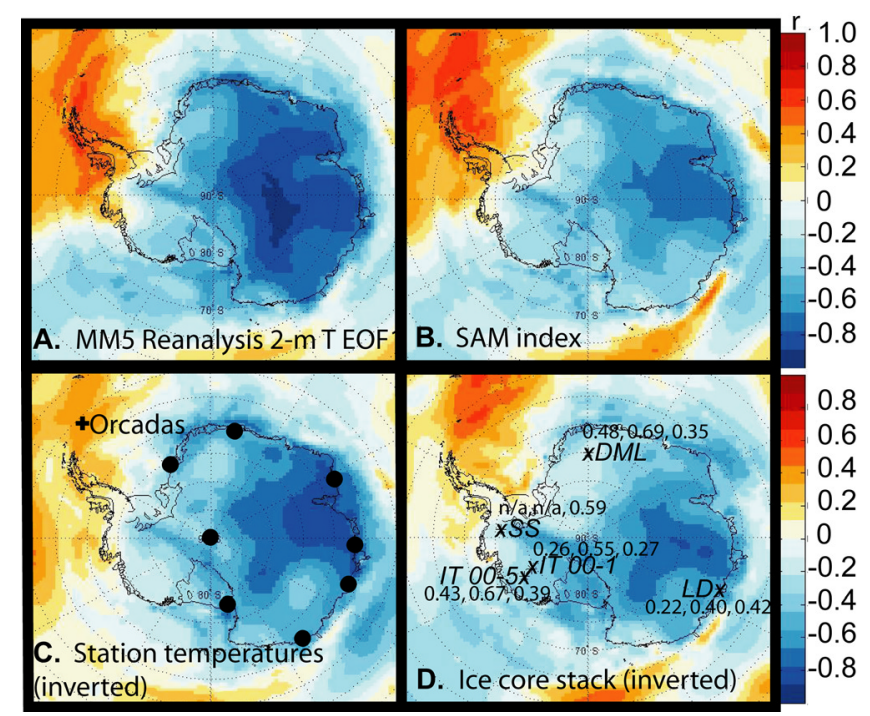

Figure 1. Correlation maps of several time series with 2-m $\mathrm{T}$ from the climate model simulation of Monaghan et al. [2006]. Negative correlations (blue) and positive correlations (red) imply negative and positive temperature anomalies, respectively: (a) The first principal component (PC) of 2-m T over the continent; (b) The SAM index; (c) The A8 composite temperature index (inverted) from the stations indicated by black dots; (d) The stacked ice core isotopic record (inverted), with core sites indicated by a black " $x$ ". At each site, the numbers indicate the correlation coefficient of the annual ice core data with the nearest gridpoint 2-m T, PC1 of 2-m T, and A8, respectively. 


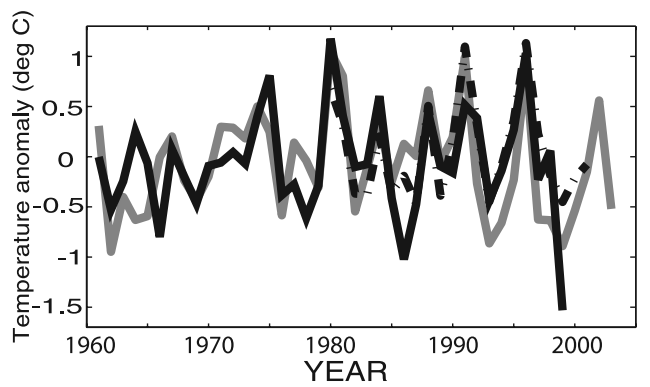

Figure 2. The gray line shows A8. Calibrated stacked ice core record (black line). Mean of 2-m T anomalies over the ice sheet (dashed line).

observed event-scale and seasonal correlations between $\delta$ and local temperature are very high [e.g., Schneider et al., 2006; van Ommen and Morgan, 1997], interannual correlations, while positive, are generally low (e.g., see Figure 1d). A GCM study has suggested that the SAM leads to an observable, organized signature in stable isotopes, with a typical positive phase SAM anomaly ranging from -0.2 to $-0.8 \%$ in $\delta^{18} \mathrm{O}$ across the continent [Noone and Simmonds, 2002]. A number of mechanisms are involved; the primary contribution to the depletion of $\delta^{18} \mathrm{O}$ is increased distillation along the path of moisture transport. The spatial pattern of isotope anomalies is analogous to and also physically linked with (via the local condensation temperature of precipitation [Noone and Simmonds, 2002; Jouzel et al., 1997]) the SAM's expression in the temperature field. At three of our widely separated sites (DML, Law Dome, and ITASE 00-5), the covariance of the SAM index and $\delta^{18} \mathrm{O}$ is significant, with a coefficient ranging from -0.30 to $-0.90 \%$ per standard deviation of the SAM index, within the range of the model calculations. Thus, the positive phase SAM is associated both with lower temperatures and depleted stable isotopes on the scale of the continent.

[10] As opposed to the traditional use of local $\delta$-temperature calibrations, our approach to temperature reconstruction is to combine multiple, annually-resolved ice core records into a single record, calibrated at the continental scale. This is supported on physical grounds both by the large-scale covariance of temperature and isotope anomalies and by the reduction of non-climate related noise when proxy records are combined. We first normalize the individual records with respect to their common 1800-1983 period of coverage. They are then combined through a weighted average on the basis of each record's detrended correlation with the A8 index (correlations indicated in Figure 1d.). This stack is significantly correlated with the A8 index at $\mathrm{r}=0.63(\mathrm{p}<0.01)$, and correlation with $2-\mathrm{m} \mathrm{T}$ shows that it corresponds to the cold continent - warm Peninsula pattern (Figure 1d), demonstrating that our stacked record captures the dominant pattern of Antarctic temperature variability. To calibrate the reconstruction, the ice core stack is adjusted to the variance and mean of the target A8 index over the 1961-1999 overlap interval. Despite local differences in the variance of temperatures, we find that A8 provides a good approximation of the variance of temperatures on the continental scale. The 2-m $\mathrm{T}$ data averaged over the ice sheet (excluding areas with negative weights in the first EOF), have a variance of $0.28^{\circ} \mathrm{C}$, which is similar to the variance of $\mathrm{A} 8$ over $1961-$ 1999 (Figure 2).

[11] In addition to the correlation coefficient, the reduction of error (RE) statistic provides a measure of reconstruction resolved variance [e.g., Jones and Widmann, 2003]. For the 1961-1999 calibration interval, the RE is 0.26 , which indicates skill relative to climatology. Given the paucity of instrumental data, we do not have the luxury of a period of data to withhold for cross-verification. However, if we consider the two halves of the calibration interval as independent calibration/verification periods, we find that the calibration statistics and verification RE scores are quite similar (Table 2), supporting confidence in the reconstruction. The $2 \sigma$ (i.e. $95 \%$ ) confidence intervals of the reconstruction are estimated as twice the root-mean-square error of the calibration period correlation times the standard deviation of A8.

[12] We note potential sources of uncertainty, including possible changes in accumulation rates that could alter the relation of stable isotopes to annual mean temperature, and changes in sea surface temperatures (at the moisture source). With regard to accumulation rates, we note that a recent study of accumulation trends finds them to be highly spatially and seasonally variable, largely canceling out over the ice sheet in the annual mean [Monaghan et al., 2006]. Seasonal accumulation trends could nonetheless alter the seasonal representativeness of the reconstruction. However, over the calibration period, the ice core stack is better correlated with the annual mean temperature than with any particular seasonal mean temperature, and the lowfrequency behavior of the stacked record is consistent with that of A8. With regard to source conditions, available deuterium excess measurements (a proxy for moisture source conditions) show no evidence of long term trends.

\section{Results and Discussion}

[13] Our reconstruction (Figure 3a) depicts significant interannual to decadal scale variability, which may be traceable to the SAM. Prior to the late 1950s, there is only indirect evidence for the strength of the SAM. The only long instrumental polar data are from Orcadas station, situated to the northeast of the Peninsula, where the positive phase of the SAM results in higher than normal temperatures $(\mathrm{r}(\mathrm{SAM}$ index, Orcadas temperature $)=0.33(\mathrm{p}<$ 0.05) see also Figure 1c.). The anti-phase temperature anomaly relationship between the Peninsula region and the continent can be represented by the significant correlation of (detrended) A8 and Orcadas temperature over 1961$2002(\mathrm{r}=-0.47, \mathrm{p}<0.01)$. The correlation of our temperature reconstruction with Orcadas temperature is nearly as high as the instrumental correlation $(\mathrm{r}=-0.44$,

Table 2. Reconstruction Statistics for Different Calibration Periods

\begin{tabular}{ccc}
\hline Period & $r(\mathrm{~A} 8, \text { ice })^{\mathrm{a}}$ & Reduction of Error \\
\hline $1961-1999$ & $0.63 \mathrm{p}<0.01$ & 0.26 calibration \\
$1961-1980$ & $0.62 \mathrm{p}<0.01$ & 0.24 verification \\
$1981-1999$ & $0.63 \mathrm{p}<0.01$ & 0.25 verification \\
\hline
\end{tabular}

${ }^{\mathrm{a}}$ Ice refers to the stacked ice core record. 


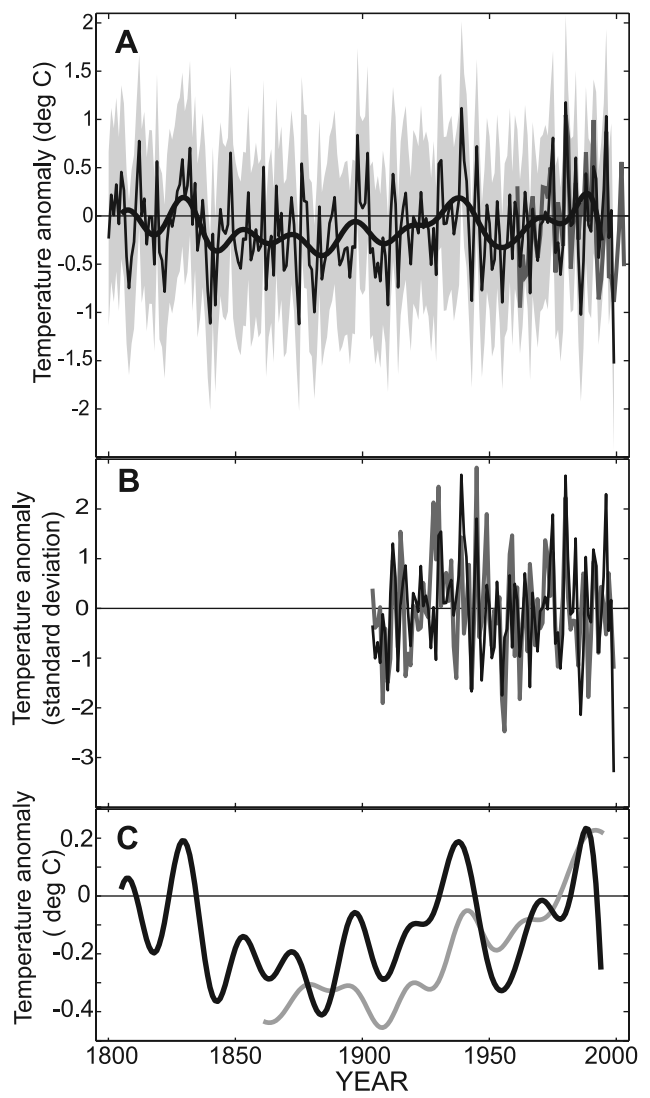

Figure 3. Antarctic temperature reconstruction: (a) Full annual resolution reconstruction (black line) with $\pm 2 \sigma$ uncertainty shaded in gray and multi-decadal smoothed version (heavy line). Instrumental calibration record, A8 (gray line); (b) Reconstruction (black line) compared with Orcadas temperature (gray line, inverted) after the linear trends have been removed; (c) Reconstruction (black line) compared with SH mean instrumental record (gray line) after a multi-decadal ( 0.05 cycles/yr cut-off) low-pass filter has been applied. In all plots, the zero line represents the 1961-1990 climatological mean.

$\mathrm{p}<0.01$ over 1904-1999), even in the pre-calibration pe$\operatorname{riod}(\mathrm{r}=-0.44, \mathrm{p}<0.01$ over 1904-1960) (Figure 3b). This result is consistent with the observed cold continent warm Peninsula pattern being a dominant feature of Antarctic climate variability. On a monthly timescale, analysis of gridded data indicates that about $17 \%$ of the spatialtemporal variance of temperature anomalies over the continent is explained by the SAM [Schneider et al., 2004], and our results suggest that on interannual to decadal timescales, a similar amount of variance is explained by the SAM over at least the last century. Large variability associated with the SAM at these timescales has also been inferred from independent reconstructions of the SAM index using station sea-level pressure [Jones and Widmann, 2004, 2003].

[14] In addition to the significant high frequency variability, our reconstruction shows an extended period of cooler than present conditions from the mid-19th to early 20th-century. Existing evidence suggests that there was not an extended positive phase SAM over this time period that could explain the lower temperatures [Jones and Widmann,
2003]. From our reconstruction, we estimate that Antarctic temperatures over the 1961-1999 calibration period were about $0.2^{\circ} \mathrm{C}$ higher than in the period $1861-1899$. Other evidence for long-term warming includes ice borehole temperature inversions at Siple Dome [Engelhardt, 2004] in West Antarctica and Law Dome [Dahl-Jensen et al., 1999] in East Antarctica. At Law Dome, the minimum ( 1850) to maximum (1990) temperature difference was quantified as $0.7^{\circ} \mathrm{C}$, which agrees with the difference of $0.6^{\circ} \mathrm{C}$ that is evident in a smoothed version of our reconstruction between the low in the 1800 s to the maximum around 1990 (Figure 3c). Some lower resolution isotopic records, at Siple Dome [Mayewski et al., 2004] and Dronning Maud Land [Isaksson et al., 1996], also suggest 20thcentury warming.

[15] It is notable that the reconstructed Antarctic temperature record is in phase with the $\mathrm{SH}$ mean instrumental temperature record [Folland et al., 2001], especially over the two well-known global warming periods, from $\sim 1910$ to $\sim 1945$ and from the 1970 s to present (Figure 3c). This phasing can be explored with cross-spectral analyses of the Antarctic versus the SH mean and the Orcadas records. Although no significant spectral peaks are present in comparison with a simple red noise continuum, the phasing and coherency relationships are informative (Figure 4). The cold continent-warm Peninsula pattern is evident in the antiphasing of the Orcadas record and the reconstruction in the broad band from about three to 10 years. The phasing with the SH mean becomes significantly coherent at the longest periods resolved, about 20 years.

[16] Since the SAM had a strong positive trend from the mid-1970s to the 1990s [Marshall, 2003], we separate temperature trends before and after 1975. From 1856 to 1975 , trends $\left({ }^{\circ} \mathrm{C}\right.$ per $\left.100 \mathrm{yr}\right)$ in the SH mean $(0.32 \pm .10$, $\mathrm{p}<0.01)$ and Antarctic record $(0.22 \pm .26, \mathrm{p}<0.10)$ are similar, while they are markedly different from $1975-1999$ $(1.40 \pm .59, \mathrm{p}<0.01$ and $-2.2 \pm 3.8$, not significant,

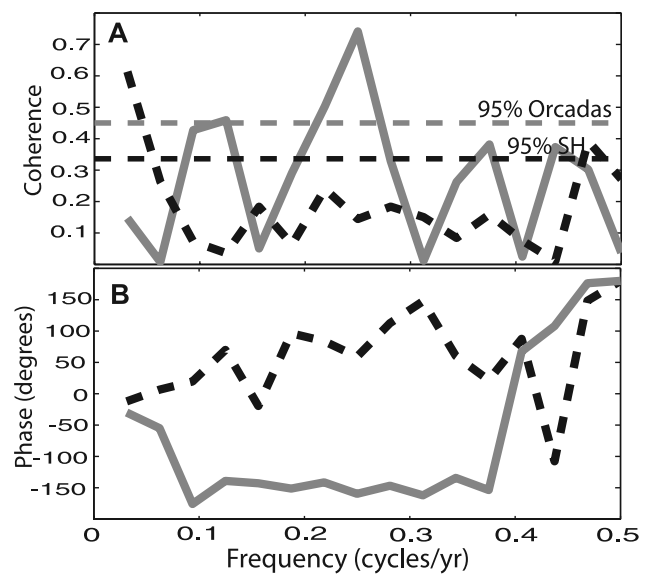

Figure 4. (a) Coherency and (b) phase estimates of the Antarctic temperature reconstruction versus the $\mathrm{SH}$ mean temperature (black dashed line) and the Orcadas temperature (gray solid line). Annual data were used, and crossspectra were estimated with a Hanning Window width of 32 years using a fast Fourier transform. 95\% confidence levels are indicated. Results are independent of linear trends in the records. 
respectively). As discussed above, the reconstruction provides evidence for long-term Antarctic warming, and the linear trend for the full period of overlap with the $\mathrm{SH}$ mean $(1856-1999)$ is an increase of $0.18 \pm .21^{\circ} \mathrm{C}$ per $100 \mathrm{yr}$ $(\mathrm{p}<0.10)$, which has greater mean and statistical significance $\left(0.23 \pm .21^{\circ} \mathrm{C}\right.$ per $\left.100 \mathrm{yr}, \mathrm{p}<0.05\right)$ if the end date, 1999 , is excluded because it is an outlier in comparison with the instrumental record. Thus, recent Antarctic cooling is superimposed on longer-term warming. These results support attribution of the cooling trend to the trend in the SAM [Thompson and Solomon, 2002], however, strong variability precludes unambiguous attribution of the SAM trend to anthropogenic forcing, such as ozone depletion.

\section{Conclusions}

[17] Our reconstruction based on high resolution stable isotope time series emphasizes that the short Antarctic instrumental records provide very limited context for assessing Antarctic temperature change, as there is large internannual to decadal scale variability, attributable in part to the SAM. In the longer-term context, our reconstruction, combined with other evidence, suggests that the Antarctic continent has experienced modest warming over the last 150 years. Similar phasing as the $\mathrm{SH}$ mean temperature record suggests that this warming may be linked to global changes and suggests that Antarctica will warm in parallel with the $\mathrm{SH}$, in general accordance with model-based predictions [e.g., Shindell and Schmidt, 2004].

[18] Acknowledgments. The authors thank G. Marshall for providing the SAM index data, E. Mosley-Thompson for Siple Station ice core data, and $\mathrm{H}$. Oerter for DML ice core data. READER data are from http:// www.antarctica.ac.uk/met/READER, Polar MM5 output is from http:// polarmet.mps.ohio-state.edu/PolarMet/ant hindcast.html, and SH mean temperature data are from http://www.cru.uea.ac.uk/cru/data/temperature/. Primary support for this work, to D.P.S., E.J.S., D.A.D., and P.A.M. is from the U.S. National Science Foundation, Office of Polar Programs (grants 0229416 and 0196105). D.P.S. acknowledges additional support from the Scientific Committee on Antarctic Research. T.v O. acknowledges support from the Australian Government's Cooperative Research Centre Program. The authors thank anonymous reviewers for their constructive comments.

\section{References}

Dahl-Jensen, D., V. Morgan, and A. Elcheikh (1999), Monte Carlo inverse modeling of the Law Dome (Antarctica) temperature profile, Ann. Glaciol., 29, $145-150$.

Dansgaard, W. (1964), Stable isotopes in precipitation, Tellus, 16, 436-468.

Engelhardt, H. (2004), Ice temperature and high geothermal heat flux at Siple Dome, West Antarctica, from borehole measurements, J. Glaciol., 50, 251-256.

EPICA Community Members (2004), Eight glacial cycles from an Antarctic ice core, Nature, 429, 623-626.

Folland, C. K., et al. (2001), Global temperature change and its uncertainties since 1861, Geophys. Res. Lett., 28, 2621-2624.

Graf, W., et al. (2002), Stable isotope records from Dronning Maud Land, Antarctica, Ann. Glaciol., 35, 195-201.

Isaksson, E., W. Karlén, N. Gundestrup, P. Mayewski, S. Whitlow, and M. Twickler (1996), A century of accumulation and temperature changes in Dronning Maud Land, Antarctica, J. Geophys. Res., 101, 7085-7094.

Jacka, T. H., W. F. Budd, and A. Holder (2004), A further assessment of surface temperature changes at stations in the Antarctic and Southern Ocean, 1949-2002, Ann. Glaciol., 39, 331-338.

Jones, J. M., and M. Widmann (2003), Instrument and tree ring based estimates of the Antarctic Oscillation, J. Clim., 16, 3511-3524.

Jones, J. M., and M. Widmann (2004), Early peak in Antarctic Oscillation index, Nature, 432, 290-291.
Jones, P. D., and M. E. Mann (2004), Climate over past millennia, Rev. Geophys., 42, RG2002, doi:10.1029/2003RG000143.

Jouzel, J., et al. (1997), Validity of the temperature reconstruction from water isotopes in ice cores, J. Geophys. Res., 102(C12), 26,47126,488, doi:10.1029/97JC01283.

Kavanaugh, J. L., and K. M. Cuffey (2003), Space and time variation of $\delta^{18} \mathrm{O}$ and $\delta \mathrm{D}$ in Antarctic snow revisited, Global Biogeochem. Cycles, 17(1), 1017, doi:10.1029/2002GB001910.

Marshall, G. J. (2003), Trends in the Southern Annular Mode from observations and reanalysis, J. Clim., 16, 4134-4143.

Mayewski, P. A., et al. (2004), A 700-year record of Southern Hemisphere extratropical climate variability, Ann. Glaciol., 39, 127-132.

Mayewski, P. A., et al. (2006), The International Trans-Antarctic Scientific Expedition (ITASE): An overview, Ann. Glaciol., 41, 180-185.

Monaghan, A. J., D. H. Bromwich, and S.-H. Wang (2006), Recent trends in Antarctic snow accumulation from Polar MM5, Philos. Trans. R. Soc. London, Ser. A, 364, 1683-1708.

Mosley-Thompson, E., L. G. Thompson, P. M. Grootes, and N. Gunderstrup (1990), Little Ice Age (Neoglacial) paleoenvironmental conditions at Siple Station, Antarctica, Ann. Glaciol., 14, 199-204.

Noone, D. C., and I. Simmonds (2002), Annular variations in moisture transport mechanisms and the abundance of $\delta^{18} \mathrm{O}$ in Antarctic Snow, J. Geophys. Res., 107(D24), 4742, doi:10.1029/2002JD002262.

Schneider, D. P., E. J. Steig, and J. C. Comiso (2004), Recent climate variability in Antarctica from satellite-derived temperature data, J. Clim., 17, 1569-1583.

Schneider, D. P., E. J. Steig, and T. van Ommen (2006), High-resolution ice core stable isotopic records from Antarctica: Towards interannual climate reconstruction, Ann. Glaciol., 41, 63-70.

Shindell, D. T., and G. A. Schmidt (2004), Southern Hemisphere climate response to ozone changes and greenhouse gas increases, Geophys. Res. Lett., 31, L18209, doi:10.1029/2004GL020724.

Steig, E. J., et al. (2006), High-resolution ice cores from US-ITASE (West Antarctica): Development and validation of chronologies and determination of precision and accuracy, Ann. Glaciol., 41, 77-84.

Thompson, D. W. J., and S. Solomon (2002), Interpretation of recent Southern Hemisphere climate change, Science, 296, 895-899.

Thompson, D. W. J., and J. M. Wallace (2000), Annular modes in extratropical circulation, part 1: Month-to-month variability, J. Clim., 13, $1000-1016$.

Turner, J., et al. (2004), The SCAR READER Project: Toward a highquality database of mean Antarctic meteorological observations, J. Clim., 17, 2890-2898.

Turner, J., et al. (2005), Antarctic climate change during the last 50 years, Int. J. Climatol., 25, 279-294.

van den Broeke, M. R., and N. P. M. van Lipzig (2004), Changes in Antarctic temperature, wind, and precipitation in response to the Antarctic Oscillation, Ann. Glaciol., 39, 119-126.

van Ommen, T. D., and V. Morgan (1997), Calibrating the ice core paleothermometer using seasonality, J. Geophys. Res., 102(D8), 93519357.

van Ommen, T. D., V. Morgan, and M. A. J. Curran (2004), Deglacial and Holocence changes in accumulation at Law Dome, Ann. Glaciol., 39, $359-365$.

Vaughan, D. G., et al. (2003), Recent rapid regional climate warming on the Antarctic Peninsula, Clim. Change, 60, 243-274.

Werner, M., and M. Heimann (2002), Modelling the interannual variability of water isotopes in Greenland and Antarctica, J. Geophys. Res., 107(D1), 4001, doi:10.1029/2001JD900253.

C. M. Bitz, Department of Atmospheric Sciences, University of Washington, Box 351640, Seattle, WA 98195, USA.

D. A. Dixon and P. A. Mayewski, Climate Change Institute, University of Maine, 303 Edward T. Bryand Global Sciences Center, Orono, ME 044695790, USA.

J. M. Jones, Institute for Coastal Research, GKSS Research Centre, MaxPlanck-Strasse 1, D-21502 Geesthacht, Germany.

D. P. Schneider and E. J. Steig, Department of Earth and Space Sciences, University of Washington, Box 351310, Seattle, WA 98195, USA. (schneidd@u.washington.edu)

T. D. van Ommen, Department of the Environment and Heritage, Australian Antarctic Division, Antarctic Climate and Ecosystems CRC, Private Bag 80, Hobart, Tas 7001, Australia. 